\title{
ANALISIS USAHA PERLEBAHAN TERHADAP PENDAPATAN KELUARGA TANI DESA SIPATUHU 1 BANDING AGUNG KABUPATEN OKU SELATAN
}

\author{
(Iman Sulaiman)
}

\begin{abstract}
The purpose of this research were to : (1) To find out how much income and contributions received from businesses in the village beekeeping Sipatuhu, (2) To determine the feasibility of beekeeping in the village Sipatuhu. This study was conducted at the District Court of Appeal Sipatuhu 1 South OKU. The determination of this research is done intentionally (purposive), arguing there is only one beekeeping businesses in the village Sipatuhu 1 District of South OKU District Court of Appeal. Research has been conducted in May and June 2013. The study found that the average cost of production enterprises Apis mellifera beekeeping for one year is $R p$ 2,144,757, Rp reception 8.53125 million / year and an income of $R p$ 6,386,493 / year, Value beekeeping business contribution to the family income Apis mellifera is small with a value of 4.8\%. Rated feasibility of Apis mellifera beekeeping Rp 47,224,232 NPV, IRR 130.81\% and Net B / C of 6.94 .
\end{abstract}

Key Words : Species of honey bees, Income.

\section{PENDAHULUAN}

\section{A. Latar Belakang}

Budidaya lebah madu sudah lama dikenal oleh masyarakat di Indonesia. Kondisi alam Indonesiayang subur memungkinkan tumbuhnya berbagai jenis tanaman yang dapat dimanfaatkan sebagai sumber pakan lebah. Tradisi memelihara lebah madu menggunakan gelodog merupakan kegiatan sambilan masyarakat pedesaan untuk memenuhi kebutuhan gizi dan menambah penghasilan (Hadisoesilo, 2011).

Model budidaya tradisional ini mengalami perubahan mendasar sejak diperkenalkannya budidaya lebah madu Apis mellifera L. pada dekade tahun 1970-an. Perubahan yang terjadi tidak hanya pada bentuk fisik peralatannya saja, tetapi juga mencakup sistem pemeliharaan dan kultur usahanya.

Penggunaan kotak pemeliharaan yang berbingkai (movable frame hive), sistem penggembalaan koloni (migratory), dan bentuk usaha yang menjurus ke industri kecil dan menengah merupakan bentuk-bentuk perubahan tersebut. Saat ini budidaya Apis mellifera L. merupakan kegiatan perlebahan yang paling dominan di Pulau Jawa jumlah koloni yang dipelihara diperkirakan mencapai sekitar 34 ribu koloni (Direktorat Jenderal Rehabilitasi Lahan dan Perhutanan Sosial, 2006).

Apis mellifera L. bukan merupakan lebah madu asli Indonesia tetapi berasal dari Eropa yang didatangkan pertama kali ke Indonesia pada tahun 1972 oleh Pramuka (Praja Muda Karana) dari Australia. Ternyata lebah madu ini mampu beradaptasi baik dengan kondisi agroklimat Indonesia. Di Indonesia produktivitas madu tertinggi pernah dicapai oleh peternak lebah madu di Jawa Timur sebesar $86 \mathrm{~kg} / \mathrm{koloni}$ pada satu musim bunga randu. Hasil madu rata-rata yang diperoleh dapat mencapai $30 \mathrm{~kg} / \mathrm{koloni} / \mathrm{tahun}$.

Dalam pengusahaan lebah madu Apis mellifera L. diperlukan pertimbangan ekonomi dalam pengambilan keputusan, karena biaya yang harus dikeluarkan tidak sedikit. Persoalannya, usaha ini sebagian besar melibatkan perternak lebah madu dengan modal terbatas dan tidak memiliki akses terhadap sumber-sumber pembiayaan. Di samping itu, pihak lain yang terkait di antaranya perbankan dan lembaga keuangan lainnya belum meyakini bahwa perlebahan merupakan usaha yang dapat dikembangkan secara komersial, oleh karena itu diperlukan informasi analisis finansial usaha lebah madu Apis mellifera L. bagi semua pihak yang berkecimpung di dalam kegiatan perlebahan (Direktorat Jenderal Rehabilitasi Lahan dan Perhutanan Sosial, 2000).

Di Desa Sipatuhu ada peternak lebah madu yang telah memulai usahanya sejak tahun 2005 . Beliau adalah M. Khodis, S.P (56 tahun), beliau memelihara lebah madu Apis mellifera L yang mampu berproduksi tinggi. Awal mula usaha budidaya lebah madu ini adalah karena Beliau menyadari bahwa lingkungan dan kondisi di Desa Sipatuhu dan sekitarnya sangat mendukung untuk ternak lebah madu seperti banyak terdapat tanaman kopi, durian, duku dan tanaman-tanaman lain yang menjadi sumber pakan lebah madu. Selain itu juga terdapat sumber air bersih serta 
jauh dari kebisingan sehingga aman untuk ternak lebah madu.

\section{B. Rumusan Masalah}

1. Berapa besar pendapatan dan kontribusi yang diterima dari usaha budidaya lebah madu di Desa Sipatuhu.

2. Bagaimana kelayakan usaha budidaya lebah madu di Desa Sipatuhu.

\section{Tujuan dan Kegunaan}

1. Untuk mengetahui berapa besar pendapatan dan kontribusi yang diterima dari usaha budidaya lebah madu di Desa Sipatuhu.

2. Untuk mengetahui kelayakan usaha budidaya lebah madu di Desa Sipatuhu.

\section{Model Pendekatan}

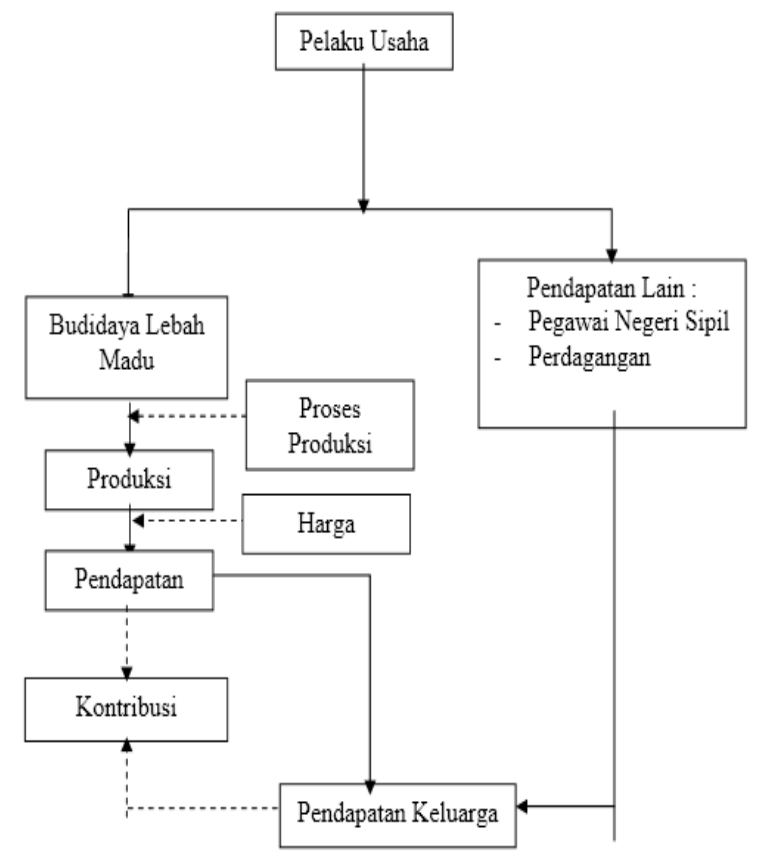

Keterangan :

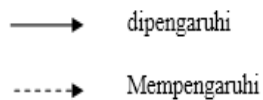

Gambar 1. Model pendekatan penelitian secara diagramatik

\section{METODOLOGI PENELITIAN}

\section{A. Tempat dan Waktu}

Penelitian ini dilakukan di Desa Sipatuhu 1 Banding Agung Kabupaten OKU Selatan. Penentuan tempat penelitian ini dilakukan secara sengaja (purposive), dengan alasan hanya ada satu pelaku usaha budidaya lebah madu di Desa Sipatuhu 1 Kecamatan Banding Agung Kabupaten
OKU Selatan. Penelitian telah dilaksanakan pada Bulan Mei sampai dengan Juni 2013.

\section{B. Metode Penelitian}

Metode penelitian yang digunakan dalam penelitian ini adalah metode studi kasus (case study). Menurut Rahardjo (2011), studi kasus adalah suatu metode untuk memahami individu yang dilakukan secara integrative dan komprehensif agar diperoleh pemahaman mendalam tentang inidividu tersebut beserta masalah yang dihadapinya dengan tujuan masalahnya dapat terselesaikan dan memperoleh perkembangan diri yang baik.

\section{Metode Penarikan Contoh}

Metode penarikan contoh secara purposive (sengaja) karena di Desa Sipatuhu hanya terdapat satu pelaku budidaya lebah. Pengumpulan data dalam penelitian ini terdiri dari data primer dan data sekunder. Data primer yang dikumpulkan adalah mengenai identitas responden, jumlah keluarga dan tingkat pendidikan, lama usaha, biaya dikeluarkan selama proses produksi serta data-data penunjang lainnya. Sedangkan data sekunder diperoleh dari lembaga-lembaga yang terkait dengan penelitian meliputi keadaan umum daerah, keadaan umum petani, serta data lain yang dianggap perlu guna menunjang penelitian yang dilaksanakan.

\section{Metode Pengolahan Data}

Metode pengolahan data dilakukan secara tabulasi dari data primer dan skunder yang diperoleh secara langsung di daerah penelitian.

1. Untuk mengetahui pendapatan dan kontribusi usaha lebah madu terhadap pendapatan keluarga tani digunakan rumus sebagai berikut (Soekartawi, 2002) :

a. Biaya Produksi

$$
\mathrm{TC}=\mathrm{FC}+\mathrm{VC}
$$

Keterangan :

TC : Total Cost (Biaya Total dalam Rupiah)

FC : Fixed Cost (Biaya Tetap dalam Rupiah)

VC : Variable Cost (Biaya Tidak Tetap Dalam Rupiah)

b.Penerimaan

$$
\mathrm{TR}=\mathrm{Y} \times \mathrm{P}
$$

Keterangan :

TR : Total Revenue (Penerimaan Rp/pp)

Y: Yield (Jumlah Produksi Rp/pp)

$\mathrm{P}$ : Price (Harga dalam Rupiah) 
c. Pendapatan

$$
\pi=\mathrm{TR}-\mathrm{TC}
$$

Keterangan :

$\pi \quad$ : Benefit / Pendapatan

TR :Total Revenue (Total Penerimaan dalam Rupiah)

TC : Total Cost (Biaya Total dalam Rupiah)

\section{d.Kontribusi}

Menurut Pujianto (1998). Untuk mengetahui besarnya nilai kontribusi terhadap pendapatan digunakan rumus :

$$
K=\left[\frac{P V T}{P U T+P L}\right] \times 100 \%
$$

Dimana :

K : Kontribusi (\%)

PUT : Pendapatan Lebah Madu (Rp/pp)

$\mathrm{PL} \quad$ : Pendapatan Lain (Rp/pp)

Keterangan :

- Kontribusi $>50 \%$ : Besar

- Kontribusi 25-49 : Sedang

- Kontribusi < 25 : Kecil

2. Untuk menghitung kelayakan usaha menurut Gittinger (1986) menggunakan rurmus berikut ini :

\section{a.NPV (Net Present Value)}

$$
N P V=\sum_{t=1}^{n} \frac{B t-C t}{(1+i)^{1}}-\mathrm{K} 0
$$

Dimana :

K0 : Kapital yang digunakan pada periode investasi

Bt : Penerimaan pada tahun $\mathrm{Ke}-\mathrm{t}$

$\mathrm{Ct}$ : Pengeluaran pada tahun $\mathrm{Ke}-\mathrm{t}$

i : Tingkat discount factor (Bunga Bank)

Kriteria untuk menerima dan menolak rencana investasi dengan metode NPV adalah sebagai berikut :
a) jika NPV > 0 maka terima.
b) Jika NPV $<0$ maka tolak.
c) Jika NPV $=0$ maka kemungkinan diterima.

\section{b.Internal Rate of Return (IRR)}

$$
I R R=i_{1}+\left(\frac{N P V_{1}}{N P V_{1}-N P V_{2}}\right)\left(i_{2}-i_{1}\right)
$$

Keterangan :
NPV1 : NPV pada tingkat discount rate tertinggi

NPV2 : NPV pada tingkat discount rate terendah

\section{i1 : Discount rate NPV 1 \\ i2 : Discount rate NPV 2}

Kriteria yang sering dipakai dalam menilai suatu usaha ditentukan oleh :

IRR > Cost of capital maka proyek dianggap layak. IRR < Cost of capital maka proyek dianggap tidak layak.

c. Net B/C

$$
\operatorname{Net} B / C=\frac{\sum \frac{(B-C)}{(1+i)^{t}}(t)}{\sum \frac{(B-C)}{(1+i)^{t}}(-)}
$$

Dimana :

$\mathrm{B}=$ Benefit/Keuntungan

$\mathrm{C}=$ Biaya

$\mathrm{t}=$ Tahun

$\mathrm{i}=$ Tingkat Bunga Bank yang berlaku

\section{HASIL DAN PEMBAHASAN}

1. Biaya Produksi

Biaya produksi yang dikeluarkan oleh Bapak M. Khodis adalah biaya pembelian koloni lebah sebanyak 30 kotak stuf, baskom, kain saringan dan corong. Penyusutan dari semua peralatan tersebut biasa disebut dengan biaya tetap. Pada saat panen Bapak M.Khodis mengeluarkan biaya pembelian botol kaca dan upah tenaga kerja. Upah yang diberikan pada setiap pemanenan madu adalah Rp 15.000/liter.

Tabel 1. Rata-rata Total Biaya Produksi Lebah Madu

\begin{tabular}{ccr}
\hline No & Uraian & Nilai (Rp/ Tahun) \\
\hline 1 & Biaya Tetap & 714.357 \\
2 & Biaya Variabel & 1.430 .400 \\
\hline & Total Biaya & 2.144 .757 \\
\hline
\end{tabular}

Sumber : Olahan Data Primer, 2013.

Dari tabel diatas dapat diketahui rata-rata biaya produksi yang dikeluarkan dalam setiap tahun adalah $\mathrm{Rp}$ 2.144.757. Biaya yang dikeluarkan meliputi biaya tetap dan biaya variabel. Biaya tetap meliputi penyusutan biaya pembelian koloni lebah sebanyak 30 kotak stuf, baskom plastik, sapu lidi, kain saringan dan 
corong. Sedangkan biaya variabel meliputi biaya pembelian botol dan upah tenaga kerja pemanenan lebah madu. Upah tenaga kerja yang diberikan adalah Rp 15.000/liter madu yang dihasilkan.

\section{Produksi, Penerimaan, dan Pendapatan.}

Produksi madu yang dihasilkan oleh lebah madu yan dipelihara oleh Bapak M. Khodis belum dapat dikatakan berproduksi tinggi hal ini dikarenakan lebah madu yang dipelihara tidak digembalakan secara langsung namun dibiarkan secara alami untuk mendapatkan pakan sendiri yang diperoleh dari bunga-bunga tanaman yang banyak terdapat di daerah sekitar pemeliharaan. Meskipun belum mampu berproduksi maksimal namun usaha budidaya lebah madu ini tetap memberikan keuntungan dan sebagai sumber pendapatan tambahan bagi keluarga Bapak $\mathrm{M}$. Khodis.

Lebah madu yang dipelihara oleh Bapak M. Khodis dipanen setiap 3 bulan sekali. Besarnya produksi madu dari tahun ke tahun terus bertambah sesuai dengan semakin bertambahnya koloni lebah serta dipengaruhi oleh musim bunga. Untuk lebih jelasnya dapat dilihat pada tabel berikut :

Tabel 2. Produksi Madu

\begin{tabular}{clrrrrrrrr}
\hline \multirow{2}{*}{ No } & \multirow{2}{*}{ Waktu Panen } & \multicolumn{6}{c}{ Tahun Produksi (Liter/pp) } & \multirow{2}{*}{ Rata-Rata } \\
& & 2008 & 2009 & 2010 & 2011 & 2012 & 2013 & \\
\hline 1 & Januari-Maret & & 21 & 30 & 36 & 45 & 42 & 34,8 \\
2 & April-Juni & 12 & 15 & 27 & 39 & 42 & 45 & 30 \\
3 & Juli-September & 9 & 9 & 18 & 30 & 33 & 27 & 21 \\
4 & Oktober-Desember & 6 & 6 & 12 & 27 & 30 & 24 & 17,5 \\
\hline & $\quad$ Jumlah & 27 & 51 & 87 & 132 & 150 & 138 & 97,5 \\
\hline & Rata-Rata & 9 & $12,7521,75$ & 33 & 37,5 & 34,5 & 25,825
\end{tabular}

Sumber: Pengolahan Data Primer, 2013.

Dari tabel tersebut dapat diketahui bahwa rata-rata produksi madu per tahun produksi adalah 97,50 liter dari 30 koloni yang dipelihara. Dengan bulan produksi tertinggi pada bulan Januari-Juni yang merupakan bulan-bulan musim tanaman berbunga.

Tabel 3. Penerimaan Madu.

\begin{tabular}{ccr}
\hline No & Uraian & \multicolumn{1}{c}{ Nilai } \\
\hline 1 & Produksi (Liter) & 97,50 \\
2 & Harga (Rp/Liter) & $87.500,00$ \\
3 & Penerimaan (Rp) & $8.531 .250,00$ \\
\hline
\end{tabular}

Sumber: Pengolahan Data Primer, 2013.

Dari 97,50 liter madu yang diproduksi diperoleh harga jual madu Rp 87.500/liter dengan total penerimaan sebesar Rp 8.531.250/tahun. Jadi besarnya pendapatan yang diterima dalam satu tahun usaha adalah $\mathrm{Rp} \mathrm{Rp} 8.531 .250$ - $\mathrm{Rp}$ 2.144.757 = Rp 6.386.493/tahun.

\section{Kontribusi Usaha Lebah Madu}

Usaha lebah madu yang dikelola oleh Bapak M. Khodis merupakan usaha sampingan yang bertujuan sebagai penambah pendapatan keluarga serta penghasil minuman kesehatan bagi keluarga. Usaha utama Bapak M. Khodis adalah sebagai seorang Pegawai Negeri Sipil Golongan III.D di Dinas BP4K Kabupaten OKU Selatan dengan gaji Rp 4.772.100/bulan. Selain itu beliau juga mempunyai saham di Koperasi Karya Utama yang memberikan tambahan pendapatan sebesar mempunyai $\mathrm{Rp} 5.750 .000 /$ bulan. Untuk mengetahui berapa besar kontribusi pendapatan yang diterima dari penjualan madu terhadap pendapatan keluarga dapat dilihat pada tabel berikut :

Tabel 4. Sumber Pendapatan Keluarga dan Nilai Kontribusinya.

\begin{tabular}{llrc}
\hline No & \multicolumn{1}{c}{$\begin{array}{c}\text { Sumber } \\
\text { Pendapatan }\end{array}$} & $\begin{array}{c}\text { Nilai } \\
(\text { Rp/Bulan } \\
\text { ) }\end{array}$ & $\begin{array}{c}\text { Kontribus } \\
\text { i }(\%)\end{array}$ \\
\hline 1 & Gaji PNS & 4.772 .100 & $43,2 \%$ \\
2 & $\begin{array}{l}\text { Perdagangan } \\
\text { Kopi }\end{array}$ & 5.750 .000 & $52,0 \%$ \\
3 & Madu & 532.208 & $4,8 \%$ \\
\hline & Total Pendapatan & $\begin{array}{r}11.054 .30 \\
8\end{array}$ & $100 \%$ \\
\hline
\end{tabular}

Sumber: Pengolahan Data Primer, 2013.

Dari tabel diatas dapat diketahui bahwa sebagai usaha sampingan usaha lebah madu mampu memberikan sumbangan pendapatan bagi keluarga tani sebesar 4,8\%. Dilihat dari kriteria penilaian kontribusi, pendapatan yang diterima dari usaha lebah madu $<25 \%$ artinya usaha ini memiliki nilai kontribusi kecil bagi pendapatan keluarga tani, namun usaha ini tetap dipertahankan sebagai sumber minuman kesehatan yang kini susah dicari kemurniannya.

\section{Net Present Value}

Untuk mengetahui kelayakan nilai kini dari usaha budidaya lebah madu yang diusahakan apakah lebih layak jika dibandingkan dengan dinvestasikan di bank maka perlu dianalisa dengan menggunakan perhitungan manfaat nilai kini dengan rumus NPV. Perhitungan dihitung sejak Tahun 2008 sampai Tahun 2013. 
Tabel 5. Biaya Produksi Usaha Lebah Madu Tahun 2008-2013.

\begin{tabular}{|c|c|c|c|c|c|c|c|}
\hline \multirow{2}{*}{ No } & \multirow{2}{*}{ Uraian } & \multicolumn{5}{|c|}{ Tahun Produksi } & \multirow{2}{*}{ Rata-Rata } \\
\hline & & $2008 \quad 2009$ & 2010 & 2011 & 2012 & 2013 & \\
\hline & Modal Awal & \multicolumn{6}{|l|}{4.623 .000} \\
\hline 2 & Biaya Tetap $(\mathrm{Rp})$ & \multicolumn{6}{|c|}{$714.357714 .357714 .357714 .357 \quad 714.357714 .357 \quad 714.357$} \\
\hline \multicolumn{8}{|c|}{3 Biaya Variabel $(\mathrm{Rp}) 432.000816 .0001 .392 .0002 .112 .000$} \\
\hline \multicolumn{8}{|c|}{ Total Biaya Produksi $\quad 5.769 .351 .530 .352 .106 .352 .826 .3$} \\
\hline
\end{tabular}

Sumber: Pengolahan Data Primer, 2013.

Dari tabel diatas dapat diketahui bahwa besarnya modal awal (investasi) pada tahun 2008 adalah Rp 4.623.000. Pada tahun 2008 sampai tahun 2013 lebah madu telah berproduksi sehingga dikeluarkan biaya saprodi untuk pembelian botol kaca dan upah tenaga kerja pemanenan madu. Setiap tahun diperkirakan ada perbaruan peralatan pendukung yang nilainya kecil namun keberadaannya sangat membantu proses pemanenan madu. Setiap tahun ada penambahan biaya produksi yang dipengaruhi oleh produksi madu yang diperoleh.

Tabel 6. Produksi, Harga dan PenerimaanUsaha Budidaya Lebah Madu.

\begin{tabular}{|c|c|c|c|c|c|c|c|}
\hline \multirow[b]{2}{*}{ No } & \multirow[b]{2}{*}{ Uraian } & \multicolumn{6}{|c|}{ Tahun Produksi } \\
\hline & & 2008 & 2009 & 2010 & 2011 & 2012 & 2013 \\
\hline 1 & Produksi (Liter) & 27 & 51 & 87 & 132 & 150 & 138 \\
\hline 2 & Harga (Rp/Liter) & 85.000 & 85.000 & 85.000 & 90.000 & 90.000 & 90.000 \\
\hline 3 & Penerimaan (Rp) & 2.295 .000 & 4.335 .000 & 7.395 .000 & 11.880 .000 & 13.500 .000 & 12.420 .000 \\
\hline
\end{tabular}

Sumber: Pengolahan Data Primer, 2013.

Pada tahun 2008 sebagai tahun awal usaha, lebah madu belum mampu berproduksi tinggi sehingga penerimaan yang diterima oleh pelaku usaha belum dapat menutupi biaya produksi yang dikeluarkan. Pada tahun 2009 produksi lebah madu mulai meningkat dari tahun ke tahun produksi madu semakin bertambah seiring dengan bertambahnya jumlah lebah perkoloni serta dipengaruhi oleh banyaknya nektar yang dikumpulkan oleh lebah. Tahun 2012 adalah tahun produksi tertinggi dengan jumlah produksi 150 liter sehingga penerimaan yang diperoleh pun lebih tinggi dari tahun-tahun sebelumnya ataupun sesudahnya.

Setelah mengetahui jumlah biaya produksi, penerimaan dan pendapatan sejak tahun 2008 sampai 2013 maka perhitungan nilai NPV dapat dihitung dengan hasil sebagai berikut:

Tabel 7. NPV 18\% Usaha Budidaya Lebah Madu.

\begin{tabular}{|c|c|c|c|c|c|c|c|c|c|}
\hline \multicolumn{2}{|c|}{ Tahum } & Investasi & $\begin{array}{c}\text { Operasional } \\
\text { Cost }\end{array}$ & Benefit & Net Benefit & Cf $18 \%$ & FV $18 \%$ & \multirow{2}{*}{$\begin{array}{r}\text { Df } 18 \% \\
0,847\end{array}$} & \multirow{2}{*}{$\frac{\text { PV } 18 \%}{6.686 .737}$} \\
\hline 1 & 2014 & & 2.045 .650 & 9.936 .000 & 7.890 .350 & & & & \\
\hline 0 & 2013 & & 2.922 .357 & 12.420 .000 & 9.497 .643 & 1,000 & 9.497 .643 & & \\
\hline & 2012 & & 3.114 .357 & 13.500 .000 & 10.385 .643 & 1,180 & 12.255 .059 & & \\
\hline 2 & 2011 & & 2.826 .357 & 11.880 .000 & 9.053 .643 & 1,392 & 12.606 .292 & & \\
\hline 3 & 2010 & & 2.106 .357 & 7.395 .000 & 5.288 .643 & 1,643 & 8.689 .409 & & \\
\hline & 2009 & & 1.530 .357 & 4.335 .000 & 2.804 .643 & 1,939 & 5.437 .579 & & \\
\hline & 2008 & 4.623 .000 & 1.146 .357 & 2.295 .000 & $(3.474 .357)$ & 2,288 & $(7.948 .488)$ & & \\
\hline & mlah & 4.623 .000 & 15.691 .793 & 61.761 .000 & 41.446 .207 & & 40.537 .495 & & $47.224 .232,17$ \\
\hline
\end{tabular}

Sumber: Pengolahan Data Primer, 2013.
Hasil analisis menunjukan dari 30 koloni lebah yang berproduksi selama 7 tahun dengan investasi sebesar Rp 4.623.000 dan biaya produksi sebesar $\mathrm{Rp} 15.691 .793$ diperoleh nilai NPV dengan jumlah $\mathrm{Rp}$ 47.224.232 pada tingkat bunga $18 \%$ dengan pendapatan bersih $\mathrm{Rp}$ 41.446.207, yang berati bahwa usaha budidaya lebah madu mempunyai nilai kelayakan usaha jika dibandingkan dengan diinvestasikan di bank.

\section{Internal Rate of Return}

Untuk menghitung besarnya persentase keuntungan yang diperoleh dari usaha budidaya lebah madu jika dibandingkan dengan suku bunga bank adalah dengan menggunakan rumus IRR. Untuk menghitung nilai IRR maka perlu dicari tahu pada suku bunga berapa berapa nilai NPV menjadi negatif.

Tabel 8. NPV Negatif pada suku bunga $132 \%$

\begin{tabular}{|c|c|c|c|c|c|c|c|c|}
\hline Tahm & Investasi & $\begin{array}{c}\text { Operasional } \\
\text { Cost }\end{array}$ & Beneffit & Net Benefit & Cf $132 \%$ & FV $132 \%$ & Df $132 \%$ & PV $132 \%$ \\
\hline $1 \quad 2014$ & - & 2.045 .650 & 9.936 .000 & 7.890 .350 & & & 0,431 & 3.401 .013 \\
\hline $0 \quad 2013$ & - & 2.922 .357 & 12.420 .000 & 9.497 .643 & 1,000 & 9.497 .643 & & \\
\hline 12012 & . & 3.114 .357 & 13.500 .000 & 10.385 .643 & 2,320 & 24.094 .691 & & \\
\hline 22011 & . & 2.826 .357 & 11.880 .000 & 9.053 .643 & 5,382 & 48.730 .327 & & \\
\hline $\begin{array}{l}3 \quad 2010 \\
\end{array}$ & . & 2.106 .357 & 7.395 .000 & 5.288 .643 & 12,487 & 66.040 .172 & & \\
\hline $4 \quad 2009$ & . & 1.530 .357 & 4.335 .000 & 2.804 .643 & 28,970 & 81.251 .148 & & \\
\hline \multirow[t]{2}{*}{$\begin{array}{ll}5 & 2008 \\
\end{array}$} & 4.623 .000 & 1.146 .357 & 2.295 .000 & $(3.474 .357)$ & 67,211 & (233.514.785) & & \\
\hline & & 15.691 .793 & 61.761 .000 & 41.446 .207 & & $(3.900 .804)$ & & (499.791) \\
\hline
\end{tabular}

Sumber: Pengolahan Data Primer, 2013.

Setelah diketahui besarnya nilai NPV negatif pada suku bunga $\mathrm{Rp} 132 \%$ dengan nilai negatif Rp 499.791, maka kita dapat menghitung besarnya nilai IRR.

Tabel 9. IRR Usaha Budidaya Lebah Madu.

\begin{tabular}{|c|c|c|}
\hline No & Uraian & Nilai \\
\hline 1 & NPV $18 \%$ & 47.224 .232 \\
\hline 2 & NPV $132 \%$ & $(499.791)$ \\
\hline
\end{tabular}

Sumber: Pengolahan Data Primer, 2013.

Dari hasil analisa diperoleh besarnya nilai IRR adalah $130,81 \%$, yang artinya $130,81 \%$ merupakan tingkat bunga maksimum yang mampu dibayar oleh pelaku usaha.

\section{Net B/C}

Net B/C digunakan untuk mengetahui perbandingan nilai $\mathrm{PV}$ positif dengan nilai $\mathrm{PV}$ negatif, jika nilai yang diperoleh lebih besar dari 1 maka usaha yang dilakukan layak dan menguntungkan.

Tabel 10. Nilai Net B/C Usaha Budidaya Lebah Madu

\begin{tabular}{ccc}
\hline No & \multicolumn{1}{c}{ Uraian } & Nilai \\
\hline \multirow{2}{*}{1} & $\sum_{\substack{18 \% \\
\text { NPV Positif }}}$ & 55.172 .719
\end{tabular}




\begin{tabular}{|c|c|c|}
\hline$?$ & $\begin{array}{l}\sum \text { NPV Negatif } \\
18 \%\end{array}$ & 7.948 .488 \\
\hline & Net B/C & 6,94 \\
\hline
\end{tabular}

Sumber: Pengolahan Data Primer, 2013.

Dari tabel diatas dapat diketahui bahwa nilai Net $\mathrm{B} / \mathrm{C}$ usaha budidaya lebah madu Apis mellifera adalah 6,94>1, yang artinya usaha budidaya lebah madu layak dan menguntungkan.

\section{IV.KESIMPULAN DAN SARAN}

\section{A. Kesimpulan}

Berdasarnya hasil penelitian dan analisis yang telah dilakukan, maka dapat ditarik kesimpulan sebagai berikut:

1. Rata-rata biaya produksi usaha budidaya lebah madu Apis mellifera selama satu tahun adalah Rp 2.144.757, penerimaan Rp 8.531.250/tahun dan pendapatan $\operatorname{Rp} 6.386 .493 /$ tahun

2. Nilai kontribusi usaha budidaya lebah madu Apis mellifera terhadap pendapatan keluarga adalah kecil dengan nilai $4,8 \%$.

3. Nilai kelayakan usaha budidaya lebah madu Apis mellifera NPV Rp 47.224.232, IRR $130,81 \%$ dan Net B/C 6,94.

\section{B.Saran}

Saran yang peneliti sampaikan adalah usaha budidaya lebah madu Apis mellifera sangat layak dikembangkan karena ditunjang dengan suhu, serta banyaknya sumber pangan lebah dan ketersediaan air bersih di Desa Sipatuhu 1 Kecamatan Banding Agung Kabupaten OKU Selatan.

\section{DAFTAR PUSTAKA}

Data Monografi Desa Sipatuhu. 2015

Departemen Agama. 2012. Al-Quran dan Terjemah. Surat An-Nahl 68-69

Departemen Perindustrian dan Perdagangan Indonesia. 2006. Perkembangan Ekspor Impor Indonesia. Jakarta

Direktorat Jenderal Rehabilitasi Lahan dan Perhutanan Sosial. 2000. Petunjuk Teknis Pengelolaan Usaha Perlebahan. Jakarta.

Direktorat Jenderal Rehabilitasi Lahan dan Perhutanan Sosial. 2006. Lokakarya Perlebahan Nasional. Jakarta
Gittinger, J. P. 1986. Analisa Ekonomi Proyekproyek Pertanian. Universitas Indonesia. Jakarta.

Hadisoesilo, S. 2011. Jenis-jenis Lebah Madu (Species of honey bees). Komunikasi In Indonesian.

Handoko, T Hani., 1999. Dasar-Dasar Manajemen Produksi Dan Operasi Edisi 1 Cetakan Keduabelas. Penerbit BPFE, Jogyakarta.

Hernanto, Fadholi., 2005. Ilmu Usahatani. Penerbit Penebar Swadaya. Anggota IKAPI Seri Pertanian, Jakarta.

Limbong dan Sitorus. 2006. Pengantar Tataniaga Pertanian Jurusan Ilmu Sosial Ekonomi Pertanian. IPB

Maykewati, S. R. 1996. Analisis Pengusahaan Lebah Madu Apis mellifera. Skripsi. Jurusan Manajemen Hutan. Fakultas Kehutanan. Institut Pertanian Bogor. Bogor. Mubyarto. 2006. Pengantar Ekonomi Pertanian. LP3S. Jakarta.

Mulyadi. 1992. Akutansi Biaya. Bagian Penerbitan STIE YKPN. Universitas Gadjah Mada. Yogyakarta.

Oldroyd and Wongsiri Asian Honey Bees. 2006. Harvard University Press. Cambridge Massachusetts and London, England.

Pramudya, B. dan N. Dewi. 1992. Ekonomi Teknik. Proyek Peningkatan Perguruan Tinggi. Institut Pertanian Bogor. Bogor.

Sjarkowi, F dan Marwan, Sufri. 2004. Managemen Agribisnis. Palembanı̨ 51 Baladad Grafiti Press

Sjarkowi, F. 2010. Managemen Agribisnıs. C V. Baldad Grafiti Press. Palembang.

Soekartawi, dkk., 2009. Ilmu Usahatani Dan Penelitian Untuk Pengembangan Petani Kecil. Penerbit UI - Press, Jakarta.

Soekartawi. 2007. Agribisnis Teori dan Aplikasinya. PT Gravindo Persada. Jakarta

Swasta, Basu dan Irawan., 2005. Manajemen Pemasaran Modern Cetakan Ke 12. Penerbit Liberty, Yogyakarta.

Verma, L. R. 1991. Beekeeping in Integrated Mountain Development. Aspect Publications: Edinburgh. In 